\title{
Wisdom Management of Large-scale Sport Events: Carriers, Patterns and Mechanism Construction
}

\author{
Xiaoyan Zhang ${ }^{1}$ Jiankang Zhang $^{2, *}$ \\ ${ }^{1,2}$ School of International Economy \& Tourism Management, Zhejiang International Studies University; Hangzhou \\ Zhejiang, China \\ ${ }^{*}$ Corresponding author. Email: zhangjk@zisu.edu.cn
}

\begin{abstract}
The technical basis of the wisdom management of large-scale sport events includes smart city, big data and other technologies. One of the carrier construction of wisdom management of large-scale sport events is the wisdom venue construction, i.e. the wisdom of the hardware and software of the venue. Second is the integration of information resources based on the construction of digital command center. The wisdom management of large-scale sport events needs to promote PPP model innovation, based on the government and social capital cooperation model to widely accept social capital; clear responsibilities to reduce coordination costs; promote the contractor to build and operate the event's venues. The mechanism construction of the wisdom management of large-scale sport events should solidify the foundation and establish a wisdom exchange platform; linkage development and build a wisdom micro-brain of largescale sport events; innovation mechanism to comply with the wisdom management of sport events.
\end{abstract}

Keywords: Large-scale sport events, wisdom management, mechanism construction

\section{INTRODUCTION}

With the development of economy and society, sports has become a very important strategic position in China's economy and society, how to implement the management of sports events into a new mode of intelligent and digital management has become a consensus on the development of a new mode of management of largescale sports events. And big data is one of the indispensable hardware conditions to realize the wisdom management. Using big data technology will greatly promote the wisdom transformation of the management mode of large-scale sports events, and the level of wisdom management will be significantly improved. In a nutshell, the opportunities brought by digitalization will lay the foundation for the wisdom management of large events, while the wisdom management will empower the operation of large-scale sport events, improve the problems existing in the original event operation and enhance the operation mechanism of large events in the future, and promote the wisdom management into the mainstream form of large- scale sport event management at home and abroad.

\section{THE TECHNICAL BASIS OF WISDOM MANAGEMENT OF LARGE- SCALE SPORT EVENTS}

\subsection{Smart cities evolve into city brains}

The progress of wisdom sports depends first of all on the development of smart cities. Building smart cities is the foundation, which requires building the digital infrastructure needed for smart cities, such as building information sharing networks, city command platforms, smart grids, smart transportation, smart water systems, etc. Hangzhou City Brain is a successful example of smart city construction, forming a smart city brain. The construction and development of smart city should take the digital era as the entry point, based on big data, fully using the Internet, cloud computing, artificial intelligence and other information technology, the technology leading and specialization is very high, accordingly, the management and operation concept is constantly changing, plus the smart city construction and operation cycle is very long, the capital demand is very large, only rely on the government side to provide funds to build their own apparently Far from being able to fully support the development needs of smart cities. Hangzhou City Brain 
provides strong technical support and guarantee for the wisdom management of large-scale events to provide public resource allocation, scientific decision-making and improve governance effectiveness [1].

\subsection{Big data technology to break the management barrier}

The wisdom management of large-scale sport events cannot be achieved without the application of big data technology. For example, in the signing ceremony of the 2022 Asian Games, the Hangzhou Asian Games Organizing Committee and Alibaba applied the Ant Blockchain Trusted Depository Technology, through which the contract will be permanently saved, which is the first time in a large comprehensive international event. It is worth mentioning that the blockchain technology will also escort the overall operation of the Hangzhou Asian Games, including travel and transportation, event tickets and other aspects. Blockchain has the following important features: decentralization, decentralization, openness, autonomy, permanence, and information stability. As an advanced computer application model for big data, blockchain is an underlying technology applicable to almost all industries, and its technical model helps to improve the level of data storage efficiency and enhance the confidentiality and security of data in the process of transmission. The innovation of data information technology has opened the barrier of wisdom management of large-scale sport events.

\section{THE CARRIER CONSTRUCTION OF WISDOM MANAGEMENT OF LARGE- SCALE SPORT EVENTS}

\subsection{Large-scale sport events wisdom stadiums construction}

The wisdom construction of sports stadiums involves two perspectives, namely, the wisdom of the hardware and software of the venues. First of all, in the hardware wisdom, one is the use of technological facilities and equipment, such as intelligent gates, lighting control systems, sound control, pool equipment, video equipment, etc.; the second is equipped with intelligent arena systems, that is, in the communication network system, arena monitoring system and arena-specific systems to introduce intelligent technology, covering automatic temperature regulation, automatic adjustment of field lighting, the intelligence of security, network integrated interconnection, etc. In addition, the system can be used in many aspects. At present, the social and economic development of record highs, and constantly emerge a large number of new technologies, the advantages of the stadium hardware facilities are no longer prominent, based on big data intelligent terminals and software and derived from a variety of wisdom service model to effectively enhance the competitiveness of the venue, that is, the software conditions of the wisdom stadium's level, mainly contains information management, data operation and interactive services. The design of wisdom venue should make full use of the resource of "5G technology". 5G, as a new communication technology, uses cellular mobile to carry out and complete the data transmission process, which is an extension of $2 \mathrm{G}, 3 \mathrm{G}$ and $4 \mathrm{G}$ technologies. $5 \mathrm{G}$ technology's advantages are: high speed and low latency, i.e. high speed propagation and low latency. 5G As a new infrastructure, it can significantly improve the mobile Internet service experience in the construction of smart stadiums[2]. The combination of 5G technology and information technology such as cloud computing and artificial intelligence effectively improves the wisdom management of various stadiums. At the same time, the upgrade and optimization of the stadium system helps to improve the efficiency of the work in the stadium, thus ensuring the fairness and impartiality of the event, which in turn helps the stadium to create more value for the society.

\subsection{Construction of digital command center for large-scale sport events}

After entering the digital era, information is a resource. The wisdom management of large-scale sport events should seize the opportunities given by digital industrialization, industry digitization and city digitization, and make full use of Hangzhou's foundation and advantages in the development of digital economy to establish a digital command center for large-scale sport events. As the organizer of large events, the work in the preparation process of the event is extremely complicated. Therefore, it is necessary to set up a special organization for large-scale sport events as a way to improve the effectiveness and accuracy of organization and management. Through the integration of many different systems such as the official website of the event, OA office system, knowledge management system, project management system and multimedia information system, a safe, stable and comprehensive command network is established for the large-scale sport event. The first step to establish a digital command center is to integrate information resources, based on big data and blockchain, with the support of digital technology and shared information, access to information resources of each participating body of sports events, including organizers, sponsors, media, consumers, regulators, etc., and realize information sharing of each participating body's department, so as to provide information basis for digital command. Secondly, the command force should be integrated, and a comprehensive command team should be formed by the event organizers, contractors, media, market supervision and other event participants to realize the collaboration mechanism of "unified management and 
unified command" and form a fixed linkage mechanism. To achieve long-term management gradually towards wisdom, technology, precision.

\section{PPP MODEL INNOVATION OF WISDOM MANAGEMENT OF LARGE- SCALE SPORT EVENTS}

\subsection{Based on government and social capital cooperation model}

Government and social capital cooperation model, or PPP (Public-Private Partnership), refers to some public service fields, the government selects social capital with the ability to provide funds by adopting a competitive approach, and the two sides enter into a contract for the social capital to provide public services. Practice shows that if the sports industry only relies on the power of a single party, it is difficult to provide capital requirements for the operation of the entire supply chain of capital, personnel and technology. The government needs to establish the government's leading position while giving full play to the role of social capital with the PPP model to help the development of wisdom management of largescale sport events. The construction of large-scale sports events is an extremely complex system that spans multiple fields, multiple professions and is integrated across the whole industry. It should be based on the pursuit of interests, supply and demand of funds, mechanism operation, staffing and other circumstances of different types of sports events, taking into account the financial strength of local governments, relevant policy factors, social capital participation and other key elements[3].

\subsection{Clear responsibilities to reduce coordination costs}

The traditional PPP financing model cannot fully meet the needs of large-scale sport event operation due to the wide range of aspects, large capital demand and complicated operation procedures, so the innovation of PPP model is needed. The most important thing is to improve the existing PPP model, improve the PPP management model from the top level design, set up a special PPP organization and management department to deal with the operation of large-scale sport events, and clearly divide the work and responsibilities among the departments, which can reduce the related coordination costs and provide a broader development space for the private sector.

\subsection{Promote contractors to build and operate venues for events}

The PFI (Private Financial Initiative) model is different from the PPP model in that it places more emphasis on private capital in social capital. The essence of the PFI model is that enterprises build and operate infrastructure projects for large events, and local governments use the funds to purchase the public services associated with them. The use of PFI model in the preparation of large-scale sports events can not only introduce sufficient capital for the operation of large-scale sport events, but also give private enterprises and other social capital more opportunities to participate in the operation of large event projects, so as to stimulate their enthusiasm and creativity.

\section{MECHANISM CONSTRUCTION OF WISDOM MANAGEMENT OF LARGE- SCALESPORT EVENTS}

\subsection{Consolidate the foundation, establish an wisdom communication platform}

In the digital era, big data can be used as the basis for breaking many traditional institutional information restrictions, facilitating the sharing of massive amounts of data and promoting the rapid development of China's digital economy. In the past 10 years, China's achievements in the field of "Internet+" have been remarkable, and various "Internet+" application models have emerged, including "Internet+ education", "Internet+ sports" and other new mobile Internet methods. Various "Internet+" application models have emerged, including "Internet+ education", "Internet+ sports" and other new mobile Internet methods are constantly innovating and developing, rapidly occupying the public eye. Specifically in the field of large-scale sport event management, it is also necessary to take the digital era as the basic entry point, use big data as the basis, establish a public platform for intelligent information exchange, promote information symmetry among event organizers, exhibitors, sponsors, service providers, staff and the public, and also provide an important opportunity and basic platform for public participation in wisdom management, effectively improve information communication efficiency, reduce information exchange costs, and provide a platform for it also provides an important opportunity and basic platform for public participation in wisdom management, effectively improves information communication efficiency, reduces information exchange costs, and solidifies the information data foundation for wisdom management of large-scale sport events, and also increases the enthusiasm and enthusiasm of public participation in management.

\subsection{Linkage development, build a large event wisdom micro-brain}

Hangzhou is famous for its "livable paradise", but also the birthplace of City Brain, the city of mobile payment, and at the forefront of technological innovation. 
Hangzhou City Brain covers 48 application scenarios including transportation, culture and tourism, safety and health, etc., which provides an important platform to promote the wisdom of urban governance in Hangzhou, and the City Brain can also be linked with large comprehensive events, i.e., in the field of large-scale sport events management, the wisdom command system of large-scale sport events is linked with the City Brain, and the data between security, traffic, fire protection, first aid, meteorology and other government departments are connected. In other words, in the field of large-scale sport event management, the wisdom command system of large-scale sport events can be linked with the city brain, and the data between various government departments such as security, traffic, fire-fighting, first aid, meteorology, etc. can be integrated, managed and intelligently analyzed through the wisdom command center to achieve cross-regional interconnection between the main event venue and sub-events, as well as crossborder interconnection of wisdom traffic, wisdom venues, wisdom security and wisdom security checks, etc. Based on Hangzhou city brain, the micro-brain of large-scale sports events under Hangzhou city brain can be built, and the wisdom micro-brain of large-scale sport events can be used to It will make scientific decisions, improve the efficiency of event operation, and promote the management of large-scale sport events from informatization to intelligence and then to final wisdom[4].

\subsection{Innovative mechanism, comply with the wisdom management of the event}

Large-scale sport events are influential, long-lasting and have complex management mechanisms. A largescale sport event is an opportunity and a challenge for a country or a region. A large-scale sport event costs a lot of money, and once it is not operated properly, it can easily cause a financial deficit. At present, there are still many shortcomings in the management mechanism of large-scale sport events in China: China lacks a specialized project management organization for large events; the market operation system of events is not perfect; the training of professional talents in management is not enough; and the preliminary planning of large events is not perfect; at the same time, the marketization and public participation of event operation are not high enough; there is a lack of information exchange public platform specifically for large sports events; it is impossible to evaluate the operation of large events in time. The lack of a public platform for information exchange for major sports events; the inability to evaluate the results of major events in a timely manner, etc. All these problems will become bottlenecks for the wisdom management of major events. Therefore, it is necessary to face the problems or potential problems in the current management mechanism of major events, and reform and innovate the management mechanism of major events to comply with the wisdom management of large-scale sport events.

\section{CONCLUSION}

Entering the digital era, the wisdom management of large-scale sport events has become a major trend. In conclusion, benefiting from the digital era, the management of large events in China has made great progress, but while we see the opportunities for development, we should also focus on the many problems that currently exist. Based on the awareness of the problems, the construction of wisdom management system of large-scale sport events is not yet perfect, the cutting-edge technology is not yet perfectly integrated into the event management system, and the concept of sports industry integration is not yet clear. The development of sports industry in the new era has a bright future, and with today's network technology and digital development tendency, the wisdom management of largescale sport events will make a rapid development.

\section{ACKNOWLEDGMENTS}

The paper accepted by the Zhejiang Provincial Social Science Planning Project "Communication Technology Deconstruction and Practice Orientation of the Intelligent Asian Games"(20NDJC159YB).

\section{REFERENCES}

[1] Jiang X J, Li S. Digitalization, globalization and the future of professional sports $[\mathrm{J}]$. Journal of Shanghai Institute of Physical Education, 2020, 44(3): 1-16.

[2] Liu J H. Sports Industry in the Internet and Digital Era [J]. Sports Science, 2019, 39(10):50-64.

[3] Dong C S, Zhang L. Logic and strategy of ubiquitous sports governance in the new era [J]. Journal of Beijing Sport University, 2019, 42(6): 111.

[4] Jiang X J. Sports industry development: new opportunities and challenges $[\mathrm{J}]$. Sports Science, 2019(7):3-11. 